\title{
Yvon Le Scanff, Gautier et le moment Corot du paysage
}

\section{Valentina Ponzetto}

\section{(2) OpenEdition}

\section{Journals}

\section{Edizione digitale}

URL: https://journals.openedition.org/studifrancesi/4746

DOI: $10.4000 /$ studifrancesi.4746

ISSN: 2421-5856

\section{Editore}

Rosenberg \& Sellier

\section{Edizione cartacea}

Data di pubblicazione: 1 avril 2012

Paginazione: $170-172$

ISSN: 0039-2944

\section{Notizia bibliografica digitale}

Valentina Ponzetto, «Yvon Le Scanff, Gautier et le moment Corot du paysage», Studi Francesi [Online],

166 ( | | LVI) | 2012, online dal 30 novembre 2015, consultato il 19 novembre 2021. URL: http:// journals.openedition.org/studifrancesi/4746 ; DOI: https://doi.org/10.4000/studifrancesi.4746

\section{Questo documento è stato generato automaticamente il 19 novembre 2021.}

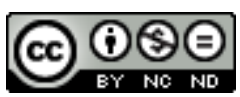

Studi Francesi è distribuita con Licenza Creative Commons Attribuzione - Non commerciale - Non opere derivate 4.0 Internazionale. 


\title{
Yvon Le Scanff, Gautier et le moment Corot du paysage
}

\author{
Valentina Ponzetto
}

\section{NOTIZIA}

YVON LE SCANFF, Gautier et le moment Corot du paysage, «Revue d'histoire littéraire de la France», 2011, 2: «La critique d'art comme genre littéraire de Diderot à Claudel», p. 405-416.

1 «Le moment Corot du paysage» altro non è, in fondo, che l'indizio di un moment romantico in pittura, segnato dall'assurgere del paesaggio a soggetto di predilezione degli artisti e dallo stemperarsi di una divisione troppo rigida che aveva segnato le scuole pittoriche fino ad allora fra un'ascendenza nordica, fiamminga, che rivendicava il realismo e lo studio dei dettagli ed una meridionale, italiana, votata alla poetica del «paesaggio storico» e della ricomposizione ideale. Per Gautier, come fa notare Yvon Le Scanff, la nuova scuola romantica tende a comprendere in un unico sistema l'eterna disputa fra queste due correnti, specchio di quella fra realismo e idealismo, ragion per cui l'artista cercherà di rifuggire tanto dai clichés d'accademia quanto da una piatta adesione al reale, per cercare invece la bellezza ideale nella natura stessa, dove essa è certo presente, ma abitualmente nascosta.

Corot è agli occhi di Gautier la figura emblematica di questa nuova scuola, capace di proporre "un retour romantique à la simplicité antique» attraverso una compresenza continua di classica bellezza ideale e di sentimento della modernità del reale. La sua ambizione di ritrovare la semplicità antica passa attraverso un sentimento romantico di desolazione e derelizione, una poetica del paysage-souvenir dipinto piuttosto come un «sentiment du paysage», uno stile che privilegia la linea e il disegno, una pennellata opaca e pastosa estremamente rara nella pittura francese. Le pagine di critica di Gautier, ampiamente citate nell'articolo, tratteggiano il mito di un Corot capace di riconciliare ingenuità e stile, primitivismo e modernismo, antico e moderno, in una 
dialettica che l'autore avvicina a quella stabilita da Schiller fra la poesia «ingenua»e «sentimentale». 